of a report on the forests by the late Mr. H. C. Hill of the India Forest Service, a Burma forest officer was appointed to the control. At present, the ten States of Malaya have each a Forest Department loosely united by a common and interchangeable staff of senior European officers and an ever-increasing body of Malays trained in the vernacular school of Kepong.

In some respects the Malay States now possess one of the most up-to-date forest departments in the Empire. That this is realized by the Government is evidenced by the recent investigation into the position of forestry and mining. Mining is one of the most important of the industries and yet the interests of the mining community tend to elash with those of agriculture and forestry. Some 10,471 square miles of the States are reserved forest (about 20 per cent of the country), yet 52.8 per cent of forest land still remains unaccounted for. Much of the reserved forest is in mountainous country. The mines are mostly concentrated in the plains. Since timber is heavy and will not bear expensive transport charges, the Forest Department wishes to develop the management of the forests which are reasonably accessible-often in the neighbourhood of existing mining tracts and into which the mining industry may wish to expand. It is recognized that the mining community takes a large amount of the produce of the forests. The problem which is now being faced is to settle, if possible for a period of years, those areas which will probably be required for the extension of mining. In this the Geological Department is affording assistance; thus allowing the Forestry Department to concentrate its works of improvement on workable, because accessible, forests which will not be liable to be expropriated. at short notice. The crucial point arising out of the arrangement is the obvious recognition by the Government of Malaya of the importance of the forests to the country and its inhabitants.

\section{Venereal Diseases in War}

According to M. Schubert (Ven. Dis. Inform., $22,327 ; 1941)$, a comparison between the incidence of venereal diseases in the Prussian Army during 1903-1913 and the four years of the War of 1914-18 showed that the average incidence was $20 \cdot 4$ per 1,000 during peace-time and 20.5 per 1,000 during the War. Contrary, therefore, to the widely prevalent but false assumption that the incidence of venereal diseases during that War was much higher than in peace, the difference was only very slight. The only increase which did occur was in the number of cases of syphilis. Of those infected during the War 67.5 per cent contracted their infection at home and only $32 \cdot 5$ per cent at the front. After demobilization of the army after the War there was a catastrophic increase in the incidence of venereal disease up to 1921-22, after which date there was a gradual decrease which in 1925-26 became increasingly noticeable and was probably due to better-regulated conditions for treatment. The decrease in the incidence of syphilis was greater than that of gonorrhœa. During the past few years chancroid has been very rarely seen in Germany. During the first nine months of the present War no increase in the incidence of venereal disease has been observed except among the troops who had been in Poland, in whom the number of syphilitic infections was low and chancroid was not found.

\section{Health of Hong Kong}

According to Dr. Selwyn Clarke, the director of medical services, Hong Kong, in his annual report for 1939, the colony's chief health problem is the large number of Chinese refugees from the SinoJapanese War. In July 1939 the number of persons entering the colony exceeded the number leaving it by 327,833 . Many of the immigrants were destitute, ill-nourished and diseased, and the overcrowded conditions in which they lived were a most serious menace to public health. The largest number of deaths in 1939 were caused by non-tuberculous diseases of the respiratory system. Tuberculosis came next, the majority of the deaths being due to the pulmonary form. 24 per cent of 1,500 refugees whose blood was examined showed a malarial infection. There were more than 9,000 cases of beriberi, 800 cases of cholera and 3,000 of influenza during the year.

\section{Announcements}

A Rockefeller Foundation grant of 25,000 dollars for research in endocrinology for five years under the direction of Dr. J. S. L. Browne, assistant professor of medicine and lecturer in pathological chemistry at McGill University, is among recent gifts to the University.

A Department of Radiology has recently been established in the medical faculty at McGill University under the direction of Dr. C. L. Peirce, radiologistin-chief at the Royal Victoria Hospital, and Dr. W. L. Ritchie, director of radiology at the Montreal General Hospital.

THE National Institute of Health of the United States Public Health Service is organizing a new research unit to be called the "Unit of Gerontology", which will deal with the diseases of the aged. Further information can be obtained from Dr. Edward J. Stieglitz, Investigations in Gerontology, National Institute of Health, United States Public Health Service, Bethesda, Maryland.

ON the recommendation of the Agricultural Research Council, the following awards of one agricultural research scholarship and two studentships for research in animal health have been made by the Ministry of Agriculture and Fisheries, and the Department of Agriculture for Scotland: H. E. Davenport, of University College, Nottingham, a research scholarship in helminthology; F. Alexander, of the Royal (Dick) Veterinary College, Edinburgh, a studentship for research in animal health; A. McDiarmid, of the Royal (Dick) Veterinary college, Edinburgh, a studentship for research in animal health. 